\title{
O CONCEITO DE REPRESENTAÇŌES COLETIVAS: UMA TRAJETÓRIA DA DIVISÃO DO TRABALHO ÀS FORMAS ELEMENTARES.
}

Márcio de Oliveira ${ }^{1}$

Resumo: Este artigo discute o conceito de representações coletivas e seu papel na sociologia durkheimiana. Investiga inicialmente a existência de uma trajetória coerente entre seu sentido inicial, nos primeiros trabalhos de Durkheim e aquele apresentado em seus últimos, quando adquire importância capital. Mostra como o conceito, após início de fôlego, perde importância para o conceito de fato social e, depois de um tempo relativamente esquecido, retorna com força nos trabalhos finais, ligado tanto à sociologia do conhecimento quanto à sociologia da religião. Para isso, são analisados todos os trabalhos em que o conceito está presente. Apresenta as etapas de seu desenvolvimento, inconstâncias e modificações. Conclui afirmando que o conceito, além de ter sido eficaz na defesa da institucionalização da sociologia enquanto disciplina científica, é ainda mais eficaz no entendimento da própria sociologia durkheimiana.

Palavras-chave: Durkheim; Representaçôes Coletivas; Conhecimento; Religião.

Abstract: This paper focuses on the concept of collective representations, his role and place in Durkheimian sociology. It searches the comprehensive trajectory between the first works and the last ones, when it acquires major significance. It shows how the concept grew up in a strong form, why it was eclipsed by the concept of social fact and, finally, how it was recovered inside sociology of knowledge and sociology of religion. It analyzes all Durkheimian works where the concept is developed. It shows his meanings, the constancies and the modifications it has suffered. It concludes by asserting that the concept succeeded by defending sociology as a scientific discipline. Besides that, it is still very successful for understanding Durkheimian sociology itself.

Keywords: Durkheim; Collective representations; Knowledge; Religion.

1 Professor de Sociologia da Universidade Federal do Paraná (UFPR/Brasil). 


\section{INTRODUÇÃO}

No ano em que As formas elementares da vida religiosa completam 100 anos de sua publicação, cabe perguntar se tudo já não foi dito sobre esse que é talvez o mais importante livro de Durkheim. Com efeito, além de ter sido cuidadosamente analisado nas duas biografias críticas sobre o autor - Lukes (1985) e Fournier (2007) - a revista Archives des Sciences Sociales de la Religion dedicou-lhe, em 1990², um número especial, com análises originais dos maiores especialistas na questão. Isambert (1992), em número da Revue Française de Sociologie, analisou as principais críticas à concepção durkheimiana de religião presentes no citado número dos Archives, dando contornos claros ao debate. Contudo, sabemos que o conhecimento científico avança sempre e novas informações e análises surgem, seja em relação ao texto mesmo, seja ainda em relação ao contexto social que viu a obra nascer, iluminando aspectos epistemológicos (a ligação da obra com suas congêneres), aspectos acadêmicos (a posição do autor dentro do campo) e mesmo subjetivos (o significado da obra dentro da psicologia própria de seu autor).

Em relação ao estudo da religião, sabemos hoje em dia que até decidir abordá-lo em forma de livro, já havia realizado estudos sobre temas tão diversos quanto a família, o direito e o crime, a vida sexual, a mulher, as organizaçôes sociais de tribos africanas, a Psicologia, a Pedagogia e a Educação, a história da Sociologia, dentre outros. O tema da religião não foi, contudo, estranho à vida de Durkheim. Nos anos letivos de 1894-1895 e 1900-1901, Durkheim ministrou cursos sobre o tema, integralmente já editados. Publicou ainda resenhas e escreveu artigos sobre a questão religiosa. Além disso, Durkheim era oriundo de uma família judia, instalada, desde inícios do século XIX, na cidade de Epinal, leste da França. Seu pai, seguindo

\footnotetext{
${ }^{2}$ Trata-se do número 69, de março de 1990. Contém diversos artigos sobre o tema da religião em Durkheim, de nomes como Daniele Hervé-Léger, José A Prades, Jean-Claude Filloux, entre outros. Está disponível em http://www.persee.fr/web/revues/home/prescript/issue/ assr_0335-5985_1990_num_69_1. Acesso em: 12 abr. 2010.
}

Debates do NER, Porto Alegre, ANo I3, N. 22 P. 67-94, JUl./DeZ. 2012 
tradição familiar, era rabino e esse título estava reservado a Durkheim. Nada mais esperado, portanto, que Durkheim escrevesse sobre o tema.

De fato, no começo de sua carreira, em 1886, Durkheim pretendia analisar o problema da religião como um fenômeno social, e não como uma escolha da consciência individual. Em 1887, Durkheim publicou uma resenha sobre o livro A irreligião do futuro, de Jean-Marie Guyau, em que disse textualmente: tratar a religião do ponto de vista do social é uma ideia nova. Qual é a tese que Durkheim apresenta então? O fenômeno religioso, escreveu, apresenta-se como um conjunto socialmente definido de prescrições de caráter obrigatório e também como um "sistema de representaçōes". Em outras palavras, trata-se de fenômeno de alguma forma mental, definido na ordem da sociedade. Diante dele, as consciências individuais, sob pena de sanções, devem dobrar-se ${ }^{3}$. Ora, tem-se aí, além da concepção de religião como fenômeno social, que não seria esquecida, o esboço da relação entre representações coletivas e fato social que seria finalmente apresentada alguns anos mais tarde, em $1895^{4}$. Mas faltava ainda uma dimensão: a questão do conhecimento. As categorias religiosas eram formas de conhecimento socialmente produzidas (fruto da associação dos indivíduos), exatamente como as representaçôes coletivas. Com efeito, em As formas, Durkheim consegue, através do emprego do conceito de representaçôes coletivas, apresentar a dimensão coletiva e científica do conhecimento produzido pela vida religiosa, em particular, mas pela vida social como um todo. Pensando as categorias religiosas como representaçôes, sociais e lógicas como qualquer outra, Durkheim concedia-lhes status epistemológico que elas ainda não tinham. Em sentido inverso, as categorias científicas também seriam coletivas, ou seja, seriam produzidas apenas em estados sociais, de efervescência, diz Durkheim. De certo modo, portanto, as categorias e práticas religiosas

\footnotetext{
${ }^{3}$ Segundo Fournier (2007, p. 134-135), a tese de Guyau aponta na direção contrária, indicando o fim de toda fé dogmática.

${ }^{4}$ De resto, neste mesmo livro, segundo Besnard (1987), Guyau apresenta o conceito de anomia como um processo de individualização das regras morais. A forma como Durkheim o utilizaria, anos depois, não é muito distante dessa, pois fala em "condutas desviantes do padrão corrente”.
} 
eram lógicas e, como as representações, materializavam e davam sentido à vida em sociedade.

A função coercitiva, que a definição de fato social tinha agregado ao conceito de representações, não permitia essa passagem porque retirava do fenômeno social seu caráter associativo, de certa forma espontâneo ou efervescente, como definiu Durkheim. Além disso, o fato social era pouco operante e dificilmente verificável, justamente porque impositivo e punitivo. Se ele servia para explicar muitas das regras morais ou ainda os comportamentos criminais (patológicos), era incapaz de explicar fenômenos coletivos como a produção de conhecimento. As representaçóes coletivas, como veremos, permite que o grupo exista, torna inteligível a realidade que o cerca, além de colocar em relação representações sobre novos e antigos fenômenos, uma das possibilidades teórico-metodológicas mais comuns desde algum tempo, em trabalhos de pesquisa exploratórios. Deve-se concluir assim que nesse último livro de Durkheim, o fato social perde espaço conceitual para o original conceito de representaçôes coletivas, devido à maior capacidade explicativa do último? Estaria Durkheim, quase ao final de sua obra, através do estudo sobre o fenômeno religioso, considerando que o melhor elemento para definir e compreender as práticas sociais eram finalmente as representaçôes coletivas?

Este artigo retoma As formas elementares não como objeto, mas como pretexto para discutir o conceito de representações coletivas e seu papel na sociologia durkheimiana. Concretamente, queremos saber: 1) É possível discernir uma trajetória coerente entre a forma como surge o conceito nos primeiros trabalhos de Durkheim e aquela trabalhada em As formas, quando adquire importância capital; e 2) Como o conceito de representações pode contribuir para requalificar a sociologia durkheimiana. Para isso, seguimos todos os trabalhos em que o conceito está presente, para apresentar, ao final, as etapas de seu desenvolvimento e coerência ou, ao contrário, suas inconstâncias e modificaçõos. 


\section{AS REPRESENTAÇÕES COLETIVAS EM DURKHEIM}

O conceito de representações coletivas é central em Durkheim. Em termos teóricos, mantém semelhanças com o conceito de fato social. Contudo, é menos imperioso e coercitivo que o último, já que é forjado no cotidiano das interaçôes sociais. Mas, como o primeiro, ele também é coletivo, exterior e objetivo. Empiricamente, as representaçôes podem representar qualquer coisa, ou seja, qualquer objeto pode ser mentalmente representado. As representações são assim funções mentais. Representando, fazemos viver o mundo. Socialmente, as representações coletivas sintetizam o que os homens pensam sobre si mesmos e sobre a realidade que os cerca. É, portanto, inicialmente, uma forma de conhecimento socialmente produzida. Resultado de esforço coletivo, elas emancipam-se das representações individuais, pautam novas ações e demonstram a existência da sociedade. As representações são coletivas e, portanto, não podem ser simplesmente reduzidas aos indivíduos. Sendo fruto da interação e dos laços sociais que os homens estabelecem entre si, elas os ultrapassam, adquirindo realidade e autonomia próprias. Aqui, as representações alcançam o terreno das práticas sociais, às quais se ligam, muito embora essa relação não tenha sido suficientemente desenvolvida por Durkheim. Em resumo, o conceito de representaçóes coletivas é ao mesmo tempo forma de conhecimento e guia para as açôes sociais, justamente os sentidos mais desenvolvidos por toda a corrente da Psicologia Social desenvolvida e liderada por Serge Moscovici ${ }^{5}$.

Não obstante isso, Lukes (1985), na biografia crítica sobre o autor, não lhe dedica um capítulo exclusivo, tal como o faz em relação aos outros temas como o conhecimento, a religião, da moral ou a educação. Na última biografia sobre Durkheim, Fournier (2007) também não dedica ao conceito uma reflexão específica, contentando-se em abordá-lo ao longo de tantas outras análises. O tema foi, contudo, bem trabalhado em livro organizado por Pickering (2000), quando de fato o conceito teve o destaque merecido.

\footnotetext{
${ }^{5}$ Francês de origem romena, Moscovici é a grande referência no campo das representações sociais na área de Psicologia Social. Tem vários livros traduzidos em português. Para maiores detalhes, ver Oliveira (2004).
}

Debates do NER, Porto Alegre, ANo I3, N. 22 P. 67-94, JUl./DeZ. 20 I2 
O que de fato as representações representam, pergunta Pickering (2000, p. 98-117)? Como entender então a posição e o papel desse conceito na obra durkheimiana? A resposta não deixa dúvidas. O conceito está em toda parte da obra de Durkheim e representa muito. Mas o conceito não havia sido criado por Durkheim. Era bem conhecido e corrente e, talvez por isso, foi utilizado de muitas maneiras. Vejamos então sua trajetória.

\section{O CONCEITO DE REPRESENTAÇÕES NOS TEXTOS}

O texto clássico Representaçôes Individuais e Representaçôes Sociais ${ }^{6}$ foi originalmente publicado no tomo VI da Revue de Métaphysique et de Morale, em maio de 1898. Naquele momento, Durkheim já havia publicado suas três grandes obras: Sobre a Divisão do Trabalho Social (1893), As Regras do Método Sociológico (1895) e O Suicídio (1897). Nessas, são várias as referências à questão das representações, frequentemente ligada à noção de consciência coletiva. Esse pequeno artigo condensa, assim, muito do que já havia sido antes trabalhado.

No primeiro tomo do livro Sobre a divisão, no capítulo intitulado Solidariedade mecânica ou por semelhanças, Durkheim parte do conceito de consciência coletiva para chegar às representações. $\mathrm{O}$ objetivo ali era fixar, conceitual e empiricamente, uma realidade considerada como estando fora do indivíduo, fora de sua consciência individual:

O conjunto de crenças e sentimentos comuns à média dos membros de uma mesma sociedade forma um sistema determinado, que tem sua vida própria; pode-se chamá-lo de consciência coletiva ou comum. Sem dúvida, ela não tem por substrato um órgão único; ela está, por definição, difusa em toda extensão da sociedade. [...] Com efeito, ela é independente das condições particulares onde os indivíduos se encontram; eles passam e ela continua. [...] Ela é o tipo psíquico da sociedade, tipo que tem suas propriedades, suas condições

\footnotetext{
${ }^{6}$ Trata-se aqui da tradução brasileira do original Représentations individuelles et représentations collectives. Devido à dimensão semântica, teria sido mais prudente traduzir literalmente o termo "collectives" por "coletivas".
} 
de existência, seu modo de desenvolvimento, assim como os tipos individuais ainda que de outra maneira. [...] As funções jurídicas, governamentais, científicas, industriais, em uma palavra, todas as funçôes especiais são de ordem psíquica, uma vez que elas consistem em sistemas de representações e de ações: contudo elas estão evidentemente fora da consciência comum. (Durkheim, 1893, p. 81)

A passagem é clara o suficiente. Primeiro aí está a referência à consciência coletiva enquanto "conjunto de crenças e sentimentos comuns à média dos indivíduos". Esse sistema tem "vida própria" e "continua". Os indivíduos "passam", ela não, reforça Durkheim. Em seguida, temos a ideia que essa consciência (coletiva ou comum) está "difusa" na sociedade. Espalha-se e não pertence a ninguém. É o tipo "psíquico da sociedade". A partir daí, Durkheim pode afirmar que suas "funções especiais" são "sistemas de representações e de ações" que se encontram "fora da consciência comum".

A relação direta entre os termos "crenças e sentimentos", "sistemas de representação" e "consciência coletiva” assim se apresenta: crenças e sentimentos comuns aos indivíduos espelham o conjunto de representações e de ações. A consciência coletiva é formada desse conjunto e nesse processo. Entre as representações coletivas e a consciência coletiva não há diferença alguma; nesse momento, são termos intercambiáveis.

Nesse livro sobre a divisão do trabalho, Durkheim quer mostrar principalmente a função da consciência coletiva, ou seja, sua capacidade de criar laços sociais solidários entre os indivíduos ou, simplesmente, de criar solidariedade, ainda que, para isso, ele a associe à morfologia (volume e densidade) da sociedade. Dito de outro modo, na ausência de divisão do trabalho, tem-se a fluida relação entre a consciência coletiva e sua organização morfológica que faz os indivíduos se aproximarem, criarem laços

\footnotetext{
${ }^{7}$ Chamando a atenção para os sentimentos comuns à média dos indivíduos, Durkheim, nesse mesmo livro, afirma, contudo, que esses sentimentos são individuais e têm origem nas "tendências que se relacionam ao organismo e aos estados do organismo", indicando aí uma origem biológica para a vida psíquica.

${ }^{8}$ Mas aqui o termo "comum" deve ser compreendido no sentido de corrente aos (que está presente nos) indivíduos, ou seja, consciência que comumente temos dos objetos e fatos.
} 
sociais, sem os quais a própria sociedade não existe. Mas o esforço maior de Durkheim aqui é tanto provar a existência da consciência coletiva quanto mostrar as diferenças e semelhanças entre as sociedades avançadas e suas congêneres inferiores. As primeiras diferenciam-se das últimas porque a divisão do trabalho torna-se uma realidade, permitindo aos indivíduos maior liberdade de expressão e de ação, mas não a expensas da consciência coletiva (ou da sociedade), que continua a existir em ambas. Em consequência, a mudança fundamental nas sociedades avançadas seria apenas no número maior de estados coletivos "[...] que deixa livre via a uma multidão crescente de dissidências individuais" (Durkheim, 1893, vol. 1, p. 159). Resumindo, na ausência da solidariedade dada, necessária, fruto da incipiente divisão do trabalho presente nas sociedades inferiores, existe a consciência coletiva, além das crenças e das representações que, englobando os indivíduos, os fazem perceber e agir de forma solidária. Fica demonstrado assim não apenas a origem dos laços sociais, mas, sobretudo, a existência da consciência coletiva (metáfora de sociedade), abrindo possibilidade para estabelecer a relação entre o sistema de representações (aquilo que o grupo pensa), e as práticas (aquilo que grupo faz), também nas sociedades industriais, exatamente o objetivo de Durkheim. Ainda que o foco principal seja demonstrar que os laços sociais (e de solidariedade) existem fora das consciências individuais, e que a divisão do trabalho é também benéfica, e não apenas causa de conflitos entre capital e trabalho, é a relação entre a consciência coletiva e as práticas o legado mais duradouro, justamente aquele que seria retomado em As formas. Contudo, o conceito de consciência coletiva era indistinto o suficiente para reconhecer as múltiplas esferas da sociedade. Ele tinha se adaptado bem à noção de morfologia social, mas não podia dar conta de sociedades diversificadas pela divisão do trabalho industrial. Lentamente, como mostram Lukes (1985, p. 229-231) e Némedi $(1995 \text {, p. } 47)^{9}$, o conceito de consciência coletiva é posto em segundo plano, assim como o é o de morfologia social. Em seu lugar, Durkheim

\footnotetext{
${ }^{9}$ Némedis (1995) afirma que do conceito de consciência coletiva, Durkheim retém apenas o princípio - ideias que se originam na sociedade - que se ajusta com sobras ao conceito de representaçôes coletivas.
}

Debates do NER, Porto Alegre, ANo I3, N. 22 P. 67-94, JUl./DeZ. 2012 
inclina-se cada vez mais pelo conceito de representaçóes coletivas, que o permite explorar a relação entre corpo social e formas mentais. Mas, antes disso, Durkheim publica As Regras do Método Sociológico.

O traço mais marcante de As Regras é a afirmação naturalista do fato social como coisa. O principal defeito é a redução epistemológica operada com a invenção do conceito de fato social. Cuin (1997, p. 171) afirma que, em As Regras, o social só aparece como quadro teórico explicativo dos comportamentos individuais porque Durkheim elimina as explicações baseadas no indivíduo ${ }^{10}$. Como bem mostram Alexander (1997) e CoenenHuther (1997), As Regras, Durkheim se vê obrigado a reduzir a complexidade do real para estabelecer a materialidade (coisa) da vida social, retomando assim a morfologia, com muitas nuances e de maneira bastante ambígua ${ }^{11}$, como causa dos comportamentos e como variável de classificação dos tipos de sociedade. Aqui reside o problema: a regra de distinção básica dos tipos de sociedade é o normativo conceito de fato social, cujo pressuposto é a definição de normalidade. Na ausência da normalidade, por exemplo, quando ocorre a doença, deve intervir a ciência, afirma Durkheim. "E aqui o pensamento moral se encontra com o projeto científico." (Coenen-Huther, 1997, p. 125). Fica demonstrado em consequência que o conceito de fato social poderia bem servir para consertar a sociedade. Mas serviria também para fazer ciência?

Em As Regras, Durkheim inova, contudo, ao propor que as representações funcionam (ou podem funcionar) como regras de conduta: "[...] elas são dotadas de uma potência imperativa e coercitiva em virtude da qual elas se impóem a ele [indivíduo], que ele queira ou não" (Durkheim, 1978, p. 2). À exterioridade, objetividade e generalidade das representações, soma-se a capacidade coercitiva. Essa capacidade coercitiva é tão mais facilmente perceptível quanto mais as representações adquirem status jurídico, ou seja, quanto mais se transformam em crimes (ofensas à vida coletiva) e são sujeitas a puniçôes. Mas essa capacidade coercitiva produz ainda um efeito, talvez

\footnotetext{
${ }^{10}$ Trata-se aqui da crítica de naturalismo sociológico feita a Durkheim.

${ }^{11}$ De fato, ora ela explicaria os comportamentos individuais, ora ainda seriam as maneiras de "ser e de fazer", como o fato social é definido ao final do primeiro capítulo de As Regras.
} 
inesperado: ela modifica o status epistemológico das representações. Dito de outro modo, quando entra em cena o fato social, Durkheim abandona as representaçôes, talvez porque perceba no primeiro um conceito mais fácil de ser definido e de ser observado. Quanto às representaçôes, o termo reaparece apenas mais duas vezes nesse livro, no segundo capítulo (Regras relativas à observação dos fatos sociais) e no quinto capítulo (Regras relativas à explicação dos fatos sociais), ambas em meio a análises já realizadas, como em relação às diferenças entre as tendências coletivas e os estados das consciências dos particulares [expressóes do próprio Durkheim]. Em resumo, ao atingir seu objetivo de demonstrar que os atos coercitivos têm origem nas tendências sociais, e são eles que, quando juridicamente normatizados, garantem a permanência da sociedade, por que Durkheim retornaria ao conceito (mais fluido e escorregadio) de representaçóes?

Ao fazer do fato social o objeto da sociologia, o método sociológico toma conta do restante do livro. Com efeito, nos capítulos que se seguem, Durkheim demonstra como observar e verificar o fato social (os capítulos sobre as regras), não retornando mais à discussão conceitual do termo de representaçōes que, em várias passagens, parece assimilado ao conceito de pré-noçôes. Trata-se talvez aqui de uma solução que pode ter ajudado na exposição de outra visão para a ciência da sociologia, sobretudo quando o grupo durkheimiano lutava para impor sua versão da atividade sociológica, mas que, do ponto de vista teórico, foi empobrecedor.

Em OSuicídio (1897), Durkheim volta ao tema das representações. No primeiro tomo, a maior parte das vezes que o termo é empregado, Durkheim o faz em seu sentido corriqueiro: aquilo que se pensa de uma determinada coisa. A aproximação do termo aqui com o de pré-noções não deixa dúvidas, como podemos observar nos seguintes exemplos. "[...] representação antecipada de sua morte"12 (Durkheim, 1897, p. 13), fazendo alusão à percepção que os animais teriam de sua própria morte. Ou ainda: "A representação que

${ }^{12}$ No original, "représentation anticipée de leur mort". 
nós fazemos disso [...]"13, quando discute o caráter imitativo do suicídio ${ }^{14}$ (Durkheim, 1897, livro 1, p. 85). Nesse livro, Durkheim trabalha a diferença, fundamental a seus olhos, entre os atos de suicídio sociologicamente explicáveis e os atos imitativos. Nos primeiros intervieram os costumes, as tradições, as representações negativas, enfim, o que diz respeito à sociedade, além de algumas disposições individuais favoráveis ${ }^{15}$, enquanto nos últimos tudo isso está ausente.

No tomo número dois deste mesmo livro, Durkheim afirma que as representações têm origem no mundo social: "As representaçóes têm antes de tudo por função exprimir uma realidade que elas não são; ao contrário, elas vêm dela"16 (Durkheim, 1897, livro 2, p. 81). Finalmente, no tomo de número três, para justificar o elemento social do suicídio, ele retorna ao conceito de representações, cunhando a afirmação atualmente clássica: "As representações coletivas são de uma natureza diferente daquela do indivíduo" ${ }^{17}$ (Durkheim, 1897, livro 3, p. 22). Contudo, nesse livro, o conceito de representaçôes coletivas parece ser mais útil à compreensão do fenômeno do suicídio.

Embora direcionando seus esforços no sentido de demonstrar o caráter coletivo das representações e o impacto dos fatos sociais sobre o comportamento dos indivíduos - trabalho ao qual se dedica tanto nas Regras quanto em O Suicídio - Durkheim não perde de vista o problema da diferenciação entre representaçóes individuais e representaçóes coletivas. Assim, em 1898, na citada Revue de Metaphysique et de Morale, ele retorna ao tema no artigo

\footnotetext{
${ }^{13}$ No original, "La représentation que nous en faisons", no caso, sobre o suicídio.

${ }^{14}$ A polêmica com Gabriel Tarde e suas "leis de imitação" é aqui mais viva do que nunca. A este respeito, ver Consolim (2011).

${ }^{15}$ Cuin (1997) afirma que essas disposições individuais contrariam o método que Durkheim acabara de expor no último livro. Assim, O Suicídio não seria o melhor exemplo de aplicação das regras metodológicas.

${ }^{16}$ No original, "Les représentations ont avant tout pour fonction d'exprimer une réalité qu'elles ne sont pas; elles en viennent au contraire".

${ }^{17}$ No original, "Les représentations collectives sont de tout une autre nature que celles de l'individu".
} 
Représentations individuelles et représentations collectives ${ }^{18}$. Segundo Bouglé, o objetivo central desse trabalho é, inicialmente, afastar-se do reducionismo que procura a origem das representaçôes individuais nas células nervosas. Em segundo lugar, diferenciar as propriedades individuais das características coletivas das representações. O modelo seguido é o da Química, ou melhor, das sínteses químicas, em que, a partir de elementos individuais, produz-se o novo, cujas propriedades não podem ser mais analiticamente decompostas ou deduzidas de suas partes individuais.

$\mathrm{O}$ artigo tem um plano simples e o argumento não surpreende. Durkheim mostra inicialmente que os estados mentais (consciência, representações etc.) têm origem psíquica e não são totalmente dependentes dos centros nervosos. $\mathrm{O}$ argumento principal aí se constrói: assim como as representações individuais são exteriores às células e às ações e reações trocadas entre os elementos nervosos, afirma Durkheim, as representaçōes coletivas também não são "[...] produzidas pelas ações e reações trocadas entre as consciências elementares" (Durkheim, 1994, p. 41). Durkheim (1994, p. 43) retoma seu argumento: "[...] as representações coletivas são exteriores às consciências individuais". $\mathrm{Na}$ página 45, encontra-se uma passagem, em itálico no original, que vale análise mais demorada. "Não pode existir vida representativa a não ser no todo formado pela reunião de elementos nervosos, do mesmo modo que a vida coletiva não existe a não ser no todo formado pela reunião de indivíduos" (Durkheim, 1994, p. 45). As representaçōes coletivas originam-se então da "reunião de indivíduos". Durkheim sugere uma pista para investigar a gênese da própria sociedade. No seio da "reunião de indivíduos", haveria ainda inúmeros estágios produzindo algo que ultrapassa as individualidades:

${ }^{18}$ Esse artigo foi republicado mais tarde no livro Sociologie et Philosophie, organizado e prefaciado por Celestin Bouglé, então professor na Universidade da Sorbonne, pela Librairie Felix Alcan (Paris), em 1924. Uma edição eletrônica dessa edição original pode ser consultada na plataforma Gallica da Bibliothèque Nationale de France (www.bnf.fr). A edição brasileira reproduziu os artigos originais de Durkheim, mas não o prefácio de Bouglé. Ver nota 6.

Debates do NER, Porto Alegre, ANo I3, N. 22 P. 67-94, JUl./DeZ. 2012 
A este respeito cabe lembrar que o todo não se forma a não ser pelo agrupamento das partes, e este agrupamento não se faz num instante, por milagre súbito, mas existe toda uma sucessão infinita de intermediários entre o estado de isolamento puro e o estado de associação caracterizada. Mas à medida que a associação se constitui, dá lugar ao nascimento de fenômenos que não se originam diretamente da natureza dos elementos associados. (Durkheim, 1994, p. 48)

Mas as representaçōes, uma vez constituídas, originam também outras:

Mas uma vez que um primeiro caudal de representaçōes foi constituído deste modo, elas se tornam, em virtude das razões que já expusemos, realidades parcialmente autônomas que gozam de uma vida própria e que têm o poder de atrair-se, repelir-se, de formar entre si sínteses de natureza diversas [...] As representações novas [...] têm por causa outras representações coletivas. [...] É na evolução religiosa que se encontram, possivelmente, os mais surpreendentes exemplos deste fenômeno (Durkeim, 1994, p. 50).

Durkheim associa os processos de autonomia e capacidade de geração às representações exatamente como fez alhures em relação aos fatos sociais. Explica ainda que nem tudo decorre da sociedade, mas de "produtos sociais" ${ }^{19}$, mostrando inclusive outro espaço prenhe de representações, a memória ${ }^{20}$. Embora curto, tem menos de 50 páginas, esse texto traz discussões centrais para a compreensão da gênese das representações, entendida aqui como dimensão associativa das individualidades ${ }^{21}$. Está indicada ainda

\footnotetext{
${ }^{19}$ Essa passagem encontra-se na nota número 16 deste capítulo.

${ }^{20}$ Durkheim a define como uma realidade relativamente autônoma que nos permite compreender fatos novos a partir de situações vividas. Maurice Halbwacs (1877-1945), um ativo membro do grupo durkheimiano, explorará essa ideia em vários de seus trabalhos. Para uma análise geral do autor e dessa perspectiva, ver Namer (2000).

${ }^{21}$ Não temos espaço nem fôlego de aprofundar a discussão, mas Durkheim aproxima-se aqui da sociologia de autores como Georges Simmel ou Max Weber, aos quais ele é normalmente oposto.
} 
aí a origem dos fenômenos religiosos e da produção do conhecimento, temas que seriam retomados mais tarde.

\section{O PREFÁCIO DA 2a EDIÇÃO DE AS REGRAS E OUTROS TRABALHOS}

Em 1901, Durkheim retoma o debate conceitual em torno das representaçōes, redefinindo inclusive o próprio sentido do objeto da sociologia. Ele é levado a fazê-lo em função das críticas que As Regras receberam. Aparentemente, uma dessas críticas o incomodou bastante, justamente aquela em que o haviam acusado de "[...] eliminar da sociologia o elemento mental" (Durkheim, 1978, p. XIX). A publicação da segunda edição é ocasião perfeita para responder aos críticos e, ao mesmo tempo, redefinir alguns conceitos e passagens.

A leitura do prefácio da segunda edição de As Regras mostra o quão importante o tema das representações tinha se tornado. O termo aparece em 12 situações $^{22}$. Inicialmente, Durkheim retoma sua afirmação segundo a qual as representações são o mental da sociedade. Em seguida, afirma que a "[...] vida social era inteiramente feita de representaçôes [...]", uma das frases de maior posteridade na sociologia durkheimiana ${ }^{23}$. A partir de então, a preocupação está em mostrar novamente - ele já havia feito isso em Sobre a divisão - que as representações coletivas não se reduzem às representações individuais. Elas são de "outra natureza”. É da natureza da sociedade que elas emanam. As representações têm essa função: afirmar que o grupo social (metáfora de sociedade) é uma entidade que tem vida própria. Finalmente, Durkheim (1978, p. XXVI) define sua função: “[...]

\footnotetext{
${ }^{22}$ Fazemos aqui referência ao aparecimento do termo no plural. Contudo, o termo aparece também no singular - representação - em outras situações, no sentido de ideia sobre um determinado objeto ou pré-noção. Nesse caso, a representação ou pré-noção impede a compreensão científica da realidade, como se pode ver na passagem seguinte: "Uma representação pode estar em estado de desempenhar esse papel [compreender a realidade], sendo mesmo assim inteiramente falsa”. (Durkheim, Regras..., op. cit., p. 16).

${ }^{23}$ A citação em questão encontra-se na primeira página desse prefácio da segunda edição.
} 
as representaçóes coletivas traduzem a maneira pela qual o grupo se enxerga a si mesmo nas relações com os objetos que o afetam.", frase que também conhecerá enorme posteridade, dando ensejo mesmo a todo o debate sobre o tema das representações, da Antropologia à Psicologia Socia ${ }^{24}$. Ele fornece ainda exemplos simples de tipos de representações coletivas: mitos, lendas populares, tradições, concepções religiosas e crenças morais. Todos eles exprimem realidades que não podem ser deduzidas ou reduzidas à esfera individual. Mas esses exemplos são também de práticas sociais, o que nem sempre é lembrado. E é justamente a associação entre representações e práticas que também seria retomada em As formas.

Em meio às suas múltiplas atividades, pequenos estudos, resenhas e seu próprio trabalho à frente da revista Annales Sociologiques, Durkheim nunca se distanciou totalmente do tema das representações, como é possível perceber inclusive em seus diversos cursos sobre o tema da educação. Sobre esse último, Durkheim dedicou vários anos letivos durante seu período de docência nas cidades de Bordéus ${ }^{25}$ e Paris, em especial após assumir em 1902, em substituição ao educador e pacifista Ferdinand Buisson (18411932), a cadeira de Ciência da Educação. Datam desse período, o livro Educação Moral, organizado e publicado em 1925 pelo sociólogo Paul Fauconnet (1874-1938) a partir do curso intitulado A Educação Moral na Escola Primária, e o livro A Evolução Pedagógica na França, a partir de um curso sobre o ensino na França ${ }^{26}$, ministrado em 1904-1905, organizado por Maurice Halbwacs (1877-1945), publicado apenas em 1938.

\footnotetext{
24 "En effet, ce que les représentations traduisent, c'est la façon dont le groupe se pense dans sesrapports avec les objets qui les affectent" (Durkheim, 1895, p. 12). Em relação à trajetória do conceito de representaçôes coletivas, ver o excelente trabalho de Pierre Moscovici (1989).

${ }^{25}$ Sob o título de Pedagogia, na Faculdade de Letras de Bordeaux, Durkheim ministrou cursos entre 1887 e 1893 e entre 1898 e 1902.

${ }^{26}$ Publicado em português sob o título de A Evolução Pedagógica na França.
} 
Nos vários artigos ${ }^{27}$ que compõem o livro Educação e Sociologia, também organizado por Fauconnet, encontramos várias referências ao tema das representaçôes próximas das teses desenvolvidas em As formas, no interior das discussōes sobre a questão da educação e do conhecimento. Inicialmente, no capítulo Educação, quando Durkheim compara as representações que se fazia então àquelas do passado:

Não representamos hoje o homem, a natureza, as causas, o próprio espaço, como eles eram representados na Idade Média; é que nossos conhecimentos e os nossos métodos científicos já não são os mesmos. [...] Antes de as ciências terem sido constituídas, era a religião que tinha esse papel; pois que toda mitologia consiste numa representação, já muito elaborada, do homem e do universo.

O papel da educação, para Durkheim, era construir um ser humano novo. Buscava-se um ideal e seu fundamento deveria justamente corresponder à representação que a sociedade se fazia de seus membros e de seu futuro. Referências ao tema das representações encontram-se igualmente no livro A Educação Moral. Nesse último, Durkheim (2008) fala ora do "sistema de representaçōes", ora das "representaçôes" feitas sobre a sociedade, ora ainda da "representação" que uma criança faz da regra moral. Em qualquer uma dessas passagens, o termo de representaçôes diz respeito àquilo que é pensado ou da transposição para o nível mental daquilo que se acredita ser a realidade. Mas diz repeito também às práticas, uma vez que as representações permitem compreender as últimas. Mitologia, religião ou ciência desempenham a mesma função cognitiva, afirma, lançando definitivamente as bases para a comparação entre ciência e religião.

${ }^{27}$ O primeiro e o segundo capítulos, Education e Pédagogie, foram publicados em 1911 no Nouveau Dictionnaire de Pédagogie et d'Instruction. O terceiro capítulo Pédagogie et Sociologie é a aula inaugural, feita em 1902, da cadeira Ciência da Educação. O último capítulo, $L$ 'évolution et le rôle de l'enseignement secondaire en France é a aula inaugural do curso para os candidatos à docência no ensino secundário, ministrado no ano letivo 1904-1905.

Debates do NER, Porto Alegre, ANo I3, N. 22 P. 67-94, JUl./DeZ. 2012 
Na primeira década do século XX, Durkheim aborda a questão das representações de forma lateral em duas resenhas. A primeira, em 1904, quando escreve sobre um livro cujo tema é a "vida sexual na Alemanha antiga". Durkheim afirma aí que a mulher, em determinado período histórico, tornou-se a representação das "elegâncias da civilização". Na segunda, em 1910, quando escreve sobre o artigo $A$ Sociologia do Conhecimento ${ }^{28}$. Durkheim expõe teses que estariam presente em As formas e, comparando as representações religiosas e as representações científicas, afirma que ambas são fruto de uma "condensação social", ou seja, fruto da própria sociedade. As representaçôes coletivas, religiosas, científicas ou outras, emanam e têm sua origem na sociedade, conclui. Esse conjunto de pequenos trabalhos é a antessala da comparação entre ciência e religião. E o que melhor permite essa comparação é sem dúvida o conceito de representações coletivas. Tanto na primeira quanto na segunda resenha, as representações são formas de retratar, de encarnar e de compreender a realidade. O sentido do termo não sofre variações de monta nesses últimos trabalhos analisados, demonstrando sem dúvida o quão consolidado estava, o quão utilizado e, assim, o quão eficaz era na sociologia durkheimiana.

\section{O CONHECIMENTO COMO REPRESENTAÇÕES COLETIVAS E OS FENÔMENOS RELIGIOSOS: PREÂMBULO DE AS FORMAS}

Dois grandes textos, separados de poucos anos um do outro, podem ser tomados como preâmbulos definitivos das principais teses de As formas. $\mathrm{O}$ primeiro é Sobre a definição dos fenômenos religiosos, publicado nos Annales Sociologiques, em 1898, e o segundo, escrito juntamente com Marcel Mauss, é Algumas formas de classificação primitiva. Contribuição ao estudo das representaçôes coletivas, igualmente publicado nos Annales Sociologiques, em 1902.

Em Sobre a definição dos fenômenos religiosos, Durkheim revisita as definições de Deus, das divindades, inclusive humanas, e as relações entre

\footnotetext{
${ }^{28}$ A resenha, intitulada $O$ problema sociológico do conhecimento, foi originalmente publicada nos Annales Sociologiques, e republicada no livro Textos, organizado por Victor Karady.
} 
as diversas sociedades e as obrigações e práticas religiosas. $\mathrm{O}$ autor conclui não por uma crítica às concepções de religião aí presentes - ele afirma, por exemplo, que não se tem uma ideia clara dos seres adorados - mas por ressaltar as representações que se fazem dela, de fato, próximas da maneira geral pela qual o "[...] primitivo se representa o mundo". Essas múltiplas representações manifestam-se através de inúmeros objetos, árvore, pedra ou vegetal. Os objetos sagrados, por sua vez, correspondem às classes de que fazem parte os grupos sociais. Mas isso não é tudo. Para Durkheim, não há objetos sagrados (e assim não há religião) sem as práticas (cultos, ritos, asceses ou sacrifícios) que lhes são devotados, cada uma delas em estreita relação com a maneira pela qual a própria sociedade se divide e se classifica. Estabelece-se assim a origem social e lógica de todo fenômeno religioso. A diferença entre as representaçóes estritamente lógicas e aquelas religiosas estaria simplesmente na crença dogmática que se atribui às últimas. Não obstante a isso, na origem de todo tipo de representação, estão formas de organização e classificação social. Em sentido inverso, é através das representaçôes que se pode observar o quão lógica e organizada é a vida em sociedade.

$\mathrm{O}$ artigo Algumas formas de classificação primitiva. Contribuição ao estudo das representaçôes coletivas situa-se em sintonia com o precedente, embora sua história particular seja distinta. Primeiro, porque é fruto da parceria que se estabeleceu entre Durkheim e Marcel Mauss. Como afirma Fournier (2007, p. 557), inicialmente Durkheim convida Mauss a escrever um trabalho sobre "a divisão do mundo segundo os clās". Em seguida, propõe-lhe uma colaboração em torno da redação de um artigo sobre as 'Classificaçóes primitivas das coisas'. Durkheim define o objetivo do artigo: "[...] mostrar como se constitui a noção de gênero e de espaço", acreditando que os gêneros não são dados, mas socialmente construídos. Mauss termina por reunir uma massa impressionante de dados, ao exame da qual, ambos concluem que existe uma correspondência entre as classificações e as formas de organização social. Fournier (2007, p. 558) afirma que essa descoberta abre um novo programa de pesquisa no seio do grupo durkheimiano, agora sobre a relação entre os tipos de organização social e as representações coletivas. Da mesma forma, o estudo das mais diversas representaçôes - contos, 
ciência, cosmologia, noções de alma, tempo etc. - deveria se tornar uma nova rubrica nos Annales sociologiques, o que acabou não acontecendo, porque, segundo Mauss, "[...] o estado da ciência não permite ainda tentar o estudo das representações enquanto tais" e que, assim, ele e Durkheim se contentaram em estudar as representações apenas em sua dimensão religiosa (Fournier, 2007, p. 558-559).

Deixando a análise dos especialistas os inúmeros exemplos, retirados das tribos da Austrália, dos EUA ou do Brasil, retém-se desse trabalho, primeiro, a correspondência, quase natural, segundo Durkheim e Mauss, entre os clãs e seus representantes totens. Em segundo lugar, a semelhança entre as classificaçôes primitivas e as classificaçōes científicas. A vida em grupo fez com que se agrupassem as coisas. "As primeiras categorias lógicas eram categorias sociais; as primeiras classes de coisas eram classes de homens, nas quais as coisas foram integradas." (Durkheim; Mauss, 1902, p. 43). Concluindo, ambos afirmam que as representações coletivas (científicas, religiosas, mitológicas etc.) são simplesmente contrapartida das formas de organização social.

Unindo esses dois artigos, o estado da arte era: as representações coletivas têm efetivamente origem nas formas de organização social e, concretamente, nas práticas sociais. Além de ser uma forma através da qual o grupo "enxerga a si mesmo e o mundo que o afeta”, as representações estão inscritas no cotidiano e na história das ações sociais. "Não simplesmente nossa noção de classificação têm uma história, mas essa própria história supõe uma préhistória considerável” (Durkheim; Mauss, 1902, p. 2). Forte dessa posição, Durkheim estava pronto para escrever seu grande livro, no qual as principais teses sobre as representaçôes e as práticas religiosas seriam retomadas.

\section{AS FORMAS ELEMENTARES E AS REPRESENTAÇÕES}

A importância do livro As Formas Elementares da Vida Religiosa, sua história e posição na obra de Durkheim, foram bastante analisados, como 
dito inicialmente. O tema da religião ${ }^{29}$, a questão da efervescência nos laços sociais e, finalmente, a questão das formas de classificação do conhecimento tão caras à filosofia da ciência - são as principais grades de leitura dessa obra. O ponto de partida inicial é: as representações religiosas, como qualquer outro tipo de representações, são formas de classificação e de pensamento coletivo; são ao mesmo tempo representações da consciência coletiva e de expressōes da realidade.

Para além do aspecto classificatório das formas da vida religiosa, Durkheim explora também a constituição mesmo dos fatos religiosos. Com efeito, eles dividem-se em dois elementos: as crenças (ou pensamentos, representaçōes etc.) e os ritos, entendidos como práticas sociais que materializam as primeiras. Ambos giram em torno das "coisas sagradas" ${ }^{30}$ e são fruto do efeito da vida em sociedade. Tem-se aqui, em primeiro lugar, o caráter coletivo das coisas sagradas, ou seja, que essas coisas só podem ser compreendidas como um fenômeno de sociedade, como representaçóes coletivas $^{31}$. Em segundo lugar, percebe-se nesse livro a união inseparável entre representações e práticas. A conclusão final não surpreende: as representaçôes religiosas são classificações lógicas da realidade que permitem a organização dos ritos, ou seja, do conjunto de práticas sociais específicas a cada forma de organização da vida coletiva.

Em termos formais, as referências ao termo de representações coletivas são numerosas. Durkheim apresenta sua definição daquilo que é comum a todas as religiōes, logo na página 16: "Na base de todos os sistemas de

${ }^{29}$ Aos que se surpreendiam com a importância do tema em sua sociologia, Durkheim respondia, já em 1899, que a religião continha as mais diversas manifestações da vida social. Ver Durkheim (1969, p. 138).

30 "Uma religião é um sistema solidário de crenças e de praticas relativas a coisas sagradas [...]”, afirma Durkheim (1912, p. 65). O traço coletivo desse fato estaria dado ainda pela instituição da igreja.

${ }^{31}$ Durkheim vai mais longe. Isso porque ele não apenas define o sagrado como fruto das representações coletivas: ele afirma que as festas religiosas são o momento onde o indivíduo sente-se fora dele mesmo; onde o indivíduo sente a efervescência sagrada da sociedade. Isso o permite afirmar: "Je ne vois dans la divinité que la société transfigurée et pensée symboliquement”. (Durkheim, 1924, p. 16). 
crenças e de todos os cultos, deve existir um certo número de representações fundamentais e de atitudes rituais [...]" A tese não é mais abandonada: crenças são representaçôes, cultos (e ritos) são práticas. Esse conjunto é indissociável. Na página 20, Durkheim explica: os primeiros sistemas de representação têm origem religiosa, ou seja, têm origem na vida coletiva. A afirmação faz sentido quando se sabe que os sentimentos religiosos surgem da efervescência criada nos atos coletivos. Temos aqui uma afirmação muito semelhante àquela presente no artigo Representaçôes individuais e representaçōes coletivas, quando afirma que "[...] as representações originam-se na "reunião de indivíduos". Ou novamente aqui: "As representaçōes religiosas são representaçôes coletivas que exprimem realidades coletivas; os ritos são maneiras de agir que nascem apenas no seio dos grupos reunidos e que estão destinadas a suscitar, a manter ou a refazer certos estados mentais desses grupos" (Durkheim, 1912, p. 21).

Durkheim fala ainda nas mitologias, nas lendas etc. como representações coletivas. No estudo sobre a religião totêmica, chama novamente a atenção para sua dupla natureza. São ao mesmo tempo crenças e ritos, representações e práticas. As crenças, aquilo que poderia parecer como somente imaterial, têm também uma origem na vida social, e encontram manifestação real nos totens, ou melhor, nas práticas totêmicas, vistas como primeira expressão material da associação entre os indivíduos. Desse momento em diante do livro, temos diversos capítulos dedicados às formas - animismo, naturismo, totemismo - da religião elementar. O livro II é dedicado às crenças e o livro III às práticas rituais. É interessante perceber, ao longo dessas centenas de páginas, o caráter constrangedor, às vezes mesmo coercitivo ${ }^{32}$ desse tipo de representações coletivas, que são as representações religiosas, e também das práticas rituais, em especial as proibidas. De fato, após haver se esforçado para consolidar os aspectos a um só tempo "coercitivo" e "constrangedor" permitido pelos fatos sociais, em As Regras, em 1912, Durkheim retorna ao

\footnotetext{
32 Ressaltamos aqui a diferença entre as expressões em francês "contrainte" e "coercition", que foram igualmente traduzidas em português, na tradução feita por Maria Isaura Pereira de Queiroz, de As Regras, por "coerção". Contudo, há empobrecimento aqui, uma vez que, também em português, algo pode constranger sem coagir, e vice-versa.
} 
conceito das representações coletivas, tendo em vista também entender as práticas. Enfatizando o caráter social ("produto de uma imensa cooperação") das representaçôes, Durkheim tem sempre em mente a relação do conceito com os comportamentos individuais efetivos. Se as representações retiram seu fundamento de regra moral (com seus constrangimentos), como não imaginar que estejam ligadas às práticas? Em consequência, as representações religiosas passam a ter caráter coercitivo. A partir dessa hipótese, qual o interesse epistemológico que Durkheim teria em utilizar ainda o conceito de fato social?

A maior eficácia conceitual das representações religiosas sobre os fatos sociais seriam reforçadas ainda por outra grande vantagem em relação aos últimos: sua capacidade de classificação. Lembremos. Segundo afirmou Durkheim, todas as crenças religiosas pressupóem uma classificação das coisas em duas classes distintas e opostas, chamadas "profano" e "sagrado" ${ }^{33}$. Pressupõem uma classificação e uma compreensão das diferenças sociais, da origem do ser humano, do universo etc. As representaçôes são "conceituais", afirma finalmente Durkheim, nas últimas páginas desse livro. Em sentido inverso, os conceitos são também representaçôes. Assim como as últimas, eles não são universais, mas circunstanciais, obra da comunidade, "acúmulo de sabedoria e de ciência ao longo do século" (Durkheim, 1912, p. 409), afirma, retomando a tese já desenvolvida em parceria com Mauss em Algumas formas de conhecimento ${ }^{34}$.

O caráter científico das representaçôes religiosas e o caráter coletivo das noções científicas seriam alguns dos temas de maior posteridade da obra de Durkheim. Não interessa aqui retornar a essa questão. Interessa, ao contrário, insistir no fato de que as representações religiosas, mas, no fundo, as representações de qualquer tipo, apresentam essa mesma capacidade de classificação. As representações classificam e são elas mesmas classificações de grupos já

${ }^{33}$ Essa oposição seria tanto aceita quanto contestada. Para maiores detalhes, ver Steiner (2005, p. 84)

${ }^{34}$ Nesse artigo, como visto, ambos haviam mostrado como essas classificações são profundamente sociais e quanto elas traduzem e, de certa forma, reproduzem a sociedade que as viu nascer.

Debates do NER, Porto Alegre, ANo I3, N. 22 P. 67-94, JUl./DeZ. 2012 
classificados. Elas têm, como afirma Steiner (2005, p. 186), uma função cognitiva porque fornecem "explicação do natural e do social". O esforço, tornado possível graças ao conceito de representações, em provar a relação entre as formas mentais coletivas e os comportamentos individuais aparece aqui, novamente, como o grande fio condutor da trajetória de Durkheim.

\section{CONCLUSÃO}

Entre março e setembro de 1917, já afetado pela doença que lhe custaria a vida antes do final daquele ano, Durkheim redigiu seu último trabalho, intitulado Introdução à moral, publicado postumamente, em 1920, em edição preparada por Marcel Mauss ${ }^{35}$. Não há aqui referências diretas ao conceito de representações. Não obstante, ele não está ausente. Durkheim relembra que a moral é uma regra de conduta, mas ela não se aplica a todas as condutas, senão àquelas que têm um sentido moral, o que varia muito de sociedade para sociedade. O "homem primitivo" representa-se as noçôes de tempo, espaço etc., de maneira bastante diferente do "homem atual", afirma. Nem todas as regras morais estão em sintonia com todas as práticas, mas as representações sim, parece dizer Durkheim. Ainda que o tema dessa introdução seja a moral, é possível entendê-la no interior da discussão teórica empírica proposta pelo conceito de representaçóes.

O conceito de representações coletivas está no começo da obra de Durkheim. Está também no final. Está nos momentos-chave, como no prefácio da segunda edição de As Regras e na conclusão de As formas. Está, ainda, aqui e ali, nas entrelinhas de muitos trabalhos considerados menores. Se Durkheim investiu no conceito de fato social, as razões parecem ter sido bem mais circunstanciais, ligadas ao mundo acadêmico de então, que propriamente científicas. $\mathrm{O}$ conceito de representações coletivas fez da sociedade um corpo relativo e histórico; confirmou e localizou o dado etnográfico em tempo e lugar específicos. Mas o tema das representações

\footnotetext{
${ }^{35}$ Em sua nota explicativa, Mauss afirma que se trata aqui do primeiro capítulo, cujo título deveria ser Concepção tradicional da Moral, do livro Moral, nunca escrito.
} 
permitiu, sobretudo, abordar as práticas sociais, dando-lhes sentido e retirando-lhes o viés irracional. Por isso o conceito de representações não se reduz a tal outro tema. Ele perpassa a obra durkheimiana e lhe confere sentido profundamente sociológico.

\section{REFERÊNCIAS}

ALEXANDER, Jeffrey. Les Règles secrètes de Durkheim. In: CUIN, Charles-Henry (sous la dir.). Durkheim, d'un siècle à l'autre. PUF: Paris, 1997. p. 191-201.

ARCHIVES DES SCIENCES SOCIALES DE LA RELIGION. n. 69, março de 1990. Disponível em: http://www.persee.fr/web/revues/home/ prescript/issue/assr_0335-5985_1990_num_69_1. Acesso em: 5 maio 2012.

BIRBAUM, Pierre. Cadres sociaux et représentations collectives dans l'oeuvre de Durkheim: l'exemple du socialisme. Revue Française de Sociologie, vol. 10, n. 1, 1969, p. 3-11.

BORLANDI, Massimo. Durkheim, les durkheimiens et la sociologie générale. Année Sociologique, v. 48, n. 1, 1998, p. 27-65.

COENEN-HUTHER, Jacques. Durkheim et l'impératif de réduction de complexité. In: CUIN, Charles-Henry (sous la dirc.). Durkheim, d'un siècle à l'autre. PUF: Paris, 1997. p. 119-130.

CONSOLIM, Márcia. Um concorrente de Durkheim: René Worms e a Revue Internationale de Sociologie. In: OLIVEIRA, Márcio de; WEISS, Raquel (Orgs.). David Emile Durkheim: a atualidade de um clássico. Curitiba: Ed. da UFPR, 2011. p. 25-54.

CUIN, Charles-Henry. Une méthode peut en cacher une autre: des Règles au Suicide. In: CUIN, Charles-Henry (sous la dir.) Durkheim, d'un siècle à l'autre. Paris: PUF, 1197. p. 169-188.

DURKHEIM. Emile. Educação e Sociologia. Petrópolis: Vozes, 2011. 
. A educação moral. Petrópolis: Vozes, 2008.

. A evolução pedagógica. Porto Alegre: Artes Médicas, 1995. . As formas elementares da vida religiosa. São Paulo: Martins Fontes, 2002.

. De la définition du phénomène religieux. L'année Sociologique, $2^{\circ}$ ano, 1898 , p. 1-28.

. De l'irreligion de l'avenir. In: DURKHEIM, Emile. Textes 2. Religion, morale, anomie. Paris: Les Editions Minuit, 1975. p. 149-165. Disponível em: http://www.uqac.uqubec.ca/zone30/Classiques_des_ sciences_sociales.index.html. Acesso em: 4 mar. 2011.

. Ética e sociologia da moral. São Paulo: Landy, 2003.

. Introduction à la morale. In: DURKHEIM, Emile. Textes 2. Religion, morale, anomie. Paris: Les Editions Minuit, 1975, p. 313-331. Disponível em: http://www.uqac.uqubec.ca/zone30/Classiques_des_sciences_sociales. index.html. Acesso em: 4 mar. 2011.

. L'avenir de la religion. In: . La science sociale et l'action. Paris: PUF, 1970, p. 305-313.

. Le sentiment religieux à l'heure actuelle. Archives des Sciences Sociales de Religion, n. 27, janvier-juin, 1969, p. 73-78

. Pragmatismo e sociologia. Tradução de Aldo Litaiff. Florianópolis/ Tubarão: Ed. da UFSC/Ed. da UNISUL, 2004.

Representações individuais e representações sociais. In:

Sociologia e Filosofia. São Paulo: Ícone, 1994. p. 9-54.

FOURNIER, Marcel. Émile Durkheim. Paris: Fayard, 2007.

- Para reescrever a biografia de Marcel Mauss. Revista Brasileira de Ciências Sociais. v. 18, n. 52, 2003, p. 5-13.

GIOVANNI, Paoletti. Durkheim et le problème de l'objectivité: une lectures des Formes Elémentaires de la Vie Religieuse. Revue Française de Sociologie, 
v. 43, n. 3, 2002, p. 437-459. Disponível em: http://www.persee.fr/web/ revues/home/prescript/issue/assr_0335-2969_2002_num_43_3_5504. Acesso em: 4 abr. 2012.

HERZLICHF, Claudine. O conceito de Representação Social e sua utilidade no campo da doença. PHYSIS: Revista de Saúde Coletiva, n. 15 (Suplemento), 2005, p. 57-70.

ISAMBERT, François-André. Une Religion de l'homme? Sur trois interprétations de la religion dans la pensée de Durkheim. Revue Française de Sociologie, v. 33, n. 3, p. 443-462. Disponível em

http://www.persee.fr/web/revues/home/prescript/article/rfsoc_00352969_1992_num_33_3_560. Acesso em: 20 maio 2011.

LEVINE, Donald N. Visôes da tradição sociológica. Rio de Janeiro: Jorge Zahar Editor, 1997.

LUKES, Steven. Bases para a interpretação de Durkheim. In: CONH, G. Sociologia: para ler os clássicos. Rio de Janeiro/São Paulo: Livros Técnicos e Científicos Editora Ltda., 1977. p. 15-46.

. Emile Durkheim. His life and work. A historical and critical study. Stanford: Stanford University Press, 1985.

MOSCOVICI, Serge. Em que sentido uma representação é social. In: . A representação social da Psicanálise. Rio de Janeiro: Jorge Zahar Editor, 1978. p. 67-81.

. Des représentations sociales aux représentations collectives, JODELET, Denise (sous la dir.). Les représentations sociales. Paris: PUF, 1989, p. 62-86.

NÉMEDIS, Dénes. Collective consciousness, morphology, and collective representations: Durkheim's Sociology of Knowledge, 1894-1900. Sociological Perspectives, v. 38, n. 1, p. 41-56, 1995.

OLIVEIRA, Márcio de. Émile Durkheim e a Sociologia brasileira. In: AUGUSTO, Maria Helena Oliva et all. Durkheim: 150 anos. Belo Horizonte: Argumentum, 2009. p. 231-257. 
Representaçôes sociais: uma teoria para a Sociologia. Estudos de Sociologia, v. 7, n. 1-2, p. 71-94, 2001.

. Representações sociais e sociedades: a contribuição de Serge Moscovici. Revista Brasileira de Ciências Sociais, v. 19, n. 55, p. 180-186, 2004.

OLIVEIRA, Márcio de; WEISS, Raquel (Orgs.). David Emile Durkheim: a atualidade de um clássico. Curitiba: Ed da UFPR, 2011.

ORTIZ, Renato. Durkheim - arquiteto e herói fundador. In: ORTIZ, Renato. Ciências Sociais e trabalho intelectual. São Paulo: Olho d'Água, 2002, p. 89-122.

. Durkheim - um percurso sociológico. In: ORTIZ, Renato. Ciências Sociais e trabalho intelectual. São Paulo: Olho d'Água, 2002. p. 123-147.

PAIS, José Machado. Das Regras do método aos métodos desregrados. Análise Social, Vol. XXX (131-132), p. 239-263, 1995.

PICKERING, William S. F. (Edited by). Durkheim and representation. London/New York: Routledge, 2000.

What do representations represent? The issue of reality. In: PICKERING, William S. F. Durkheim and representation, op. cit., 2000. p. 98-117.

PINHEIRO F., Fernando. A noção de representação em Durkheim. Lua Nova, n. 61, p. 139-155, 2004.

PIZZORNO, A. Uma leitura atual de Durkheim. In: CONH, G. Sociologia: para ler os clássicos. Rio de Janeiro/São Paulo: Livros Técnicos e Científicos Editora Ltda., 1977. p. 47-84.

REX, John. Problemas fundamentais da Teoria Sociológica. Rio de Janeiro: Jorge Zahar Editor, 1973.

STEINER, Philippe. A tradição francesa de crítica sociológica à economia política. Política e sociedade, v. 8, n. 15, p. 13-45, 2009.

. La sociologie de Durkheim. Paris: Ed de la Découverte, 1994. 
VALADE, Bernard (Coord. par). Durkheim et l'institution de la sociologie. Paris: PUF, 2008.

WATTS MILLER, William. Durkheim, morals and modernity. London: University College of London Press, 1996. 